\title{
Impact of estrogens in males and androgens in females
}

\author{
Stephen R. Hammes ${ }^{1}$ and Ellis R. Levin ${ }^{2,3}$ \\ 'Division of Endocrinology and Metabolism, Department of Medicine, University of Rochester School of Medicine, Rochester, New York, USA. ²Departments of Medicine and Biochemistry, UCI, Irvine, \\ California, USA. ${ }^{3}$ Division of Endocrinology, UCI and United States Department of Veterans Affairs Medical Center, Long Beach, California, USA.
}

\begin{abstract}
Androgens and estrogens are known to be critical regulators of mammalian physiology and development. While these two classes of steroids share similar structures (in general, estrogens are derived from androgens via the enzyme aromatase), they subserve markedly different functions via their specific receptors. In the past, estrogens such as estradiol were thought to be most important in the regulation of female biology, while androgens such as testosterone and dihydrotestosterone were believed to primarily modulate development and physiology in males. However, the emergence of patients with deficiencies in androgen or estrogen hormone synthesis or actions, as well as the development of animal models that specifically target androgen- or estrogen-mediated signaling pathways, have revealed that estrogens and androgens regulate critical biological and pathological processes in both males and females. In fact, the concept of "male" and "female" hormones is an oversimplification of a complex developmental and biological network of steroid actions that directly impacts many organs. In this Review, we will discuss important roles of estrogens in males and androgens in females.
\end{abstract}

\section{Introduction}

The sex steroids testosterone and estradiol, the latter of which is derived from the former, play important developmental and functional roles in many organs of male and female humans, respectively (1). These roles include actions in the reproductive organs, brain, bones, heart and vasculature, and liver. However, substantial evidence now indicates that endogenous estrogens in men and androgens in women are not only integral to health, but can additionally promote aspects of disease.

Ovaries are the primary source of estrogen in females, and levels fluctuate with phases of the menstrual cycle. Local estrogen production is also present in female tissues such as the bone and breast secondary to aromatization of androgens. In males, both testicular Leydig and Sertoli cells synthesize estrogen that likely remains relatively local, while most estrogen in the blood comes from aromatization of testosterone in peripheral organs. In both males and females, estrogens act upon binding either of the two isoforms of estrogen receptors (ERs), ER $\alpha$ (1) and ER $\beta$ (2), which then modulate nuclear transcriptional responses as well as extranuclear kinase and $\mathrm{G}$ protein signaling. This results from multiple cellular pools of ERs acting both in nuclear and extranuclear locations.

Similarly to estrogen, testosterone is synthesized by both males and females, albeit in different quantities. Testosterone production by Leydig cells in the testes of males is 7 to 8 times higher than that produced by the ovaries in females (3). Testosterone is converted to dihydrotestosterone (DHT), and both of these bind the androgen receptor (AR), although DHT has a greater affinity and cannot be aromatized to estrogen. Like estrogen, androgens act in both nuclear and extranuclear domains of many cells in multiple organs.

Conflict of interest: The authors have declared that no conflict of interest exists. Copyright: (5) 2019, American Society for Clinical Investigation.

Reference information: / Clin Invest. 2019;129(5):1818-1826.

https://doi.org/10.1172/JCI125755.
We propose that the crossover effects of androgens and estrogens in females and males, respectively, are likely programmed through evolution to ensure the health of humans during their reproductive years, thereby promoting survival. This Review will examine physiological human estrogen actions in males and androgen actions in females, with a focus on steroid hormone actions in the bone, reproductive system, CNS, and metabolism. In addition, we will describe recent data implicating androgen in breast cancer and estrogen in prostate cancer growth and progression.

\section{Estrogen action in men}

Preface. $17-\beta$-estradiol (E2) is the common form of serum and tissue estrogen in men and women. The CYP19A1 gene encodes the aromatase enzyme that converts testosterone to E2 in both sexes (4). Aromatase is expressed in many organs and cells; thus, local production and action of E2 in men is likely physiologically relevant (5). Strong support for important roles of E2 comes from studies in men with inactivating mutations of either ER $\alpha$ or aromatase $(6,7)$. E2 insensitivity was found in a 28 -year-old man diagnosed with a homozygous ER $\alpha$ mutation that produced a truncated nonfunctional protein (6). The individual presented with continued linear growth and tall stature due in part to unfused epiphyses, despite normal serum testosterone. Significant osteoporosis was noted, indicating that endogenous estrogen and ER $\alpha$ are important in men for normal bone growth and development. This individual was also overweight for his height and showed excess abdominal fat. Elevated endogenous estrogen levels in this individual failed to suppress the pituitary gonadotropins, luteinizing and follicle-stimulating hormones ( $\mathrm{LH}$ and $\mathrm{FSH}$, respectively) in the absence of the functional ER $\alpha$ receptor. Thus, while direct action of male sex steroids at ARs in the brain may play some role in negative feedback that regulates $\mathrm{LH}$ and FSH, estrogen signaling via $E R \alpha$ is also required.

Similarly, men who are functionally deficient in aromatase activity, and therefore cannot make estrogens, have abnormalities 
of bone formation, glucose and lipid metabolism (trending toward the metabolic syndrome), and reproductive tract development and function (ultimately impairing fertility) $(8,9)$, many of which improve with estradiol. These examples in human males confirm the importance of estrogen in normal male physiology and are supported by studies in ER $\alpha$-deficient mice, where similar phenotypes are observed $(6,7,10)$.

Bone development and function. Many studies have shown important effects of estrogen for bone health in elderly men and for bone development in young men. In the latter, there is evidence that estrogen strongly contributes to the closure of the epiphyses, thus limiting linear growth (11). This role of E2 is consistent with periosteal bone expansion during puberty, which is also seen with E2 replacement in men with aromatase gene mutations $(8,9,11)$.

In elderly hypogonadal men with elevated markers of bone resorption characteristic of enhanced osteoclast activity, testosterone replacement is minimally effective in suppressing these markers (12). In contrast, estrogen replacement strongly suppresses the increase of bone resorption markers. The authors of this study conclude that in men, estrogen accounted for approximately $70 \%$ of antiresorptive effects on bone, with testosterone contributing about $30 \%$. These findings are consistent with osteopenia/osteoporosis observed in men with either mutated aromatase or ER $\alpha$ genes $(6,7)$. Studies in elderly men treated with an aromatase inhibitor provide additional support for estrogen's role in preserving bone (13).

Mechanistically, in mouse models, estrogen suppresses IL-6dependent osteoclast differentiation, which then may attenuate bone loss. However, TNF- $\alpha$ likely is more important for mediating estrogen deficiency-related bone loss, since ovariectomy increases bone marrow production of TNF- $\alpha$, accompanied by bone loss, while ovariectomy in TNF- $\alpha$-deficient mice does not lead to bone loss (14). The roles of TNF- $\alpha$ and possibly IL-1 $\beta$ suppression in mediating the antiresorptive effects of estrogen were confirmed in studies in women (15). However, comparable studies have not been done in men. Other purported mediators of osteoclast development and/or resorption in females that are inhibited by estrogen include activation of NF- $\mathrm{BB}$ and sclerostin (16). However, again, little has been validated in men.

While aromatase in bone cells facilitates the local estrogen synthesis needed for bone formation in normal men, different conclusions have been drawn from genetic mouse models of ER $\alpha$ deletion in osteoblast (bone-forming) precursor cells, suggesting little contribution by E2 and ER $\alpha$ in male mice. A potential explanation is that estrogen effects in humans are mainly on cortical bone that comprises approximately $80 \%$ of the human skeleton, whereas cortical bone is quite different in the mouse and may be regulated differently by estrogens (17). This might be clinically relevant to prevent osteoporosis-related fractures in long bones of both human sexes.

An important role for ER $\beta$ in bone metabolism in humans is not well supported. Two female mouse models, K/G-ER $\beta$-KO (18) and C-ER $\beta$-KO (19), were created. The first model $(K / G)$ showed increased cortical bone mineral density early in development (20) and increased cortical and trabecular density at 12 months of age (21). However, the C-ER $\beta$-KO female mouse model showed no difference in cortical bone thickness and mineral density compared with WT mice, while trabecular bone showed increased mineralizing surface, likely due to reduced bone resorption (22). The cortical bone discrepancy may result from completeness of the $\mathrm{ER} \beta$ deletion. Interestingly, the male $\mathrm{K} / \mathrm{G}$ mice showed no bone abnormalities (20). Deletion of ER $\beta$ in osteoprogenitor cells also showed increased trabecular but not cortical bone mass in female mice (23). Overall, these results indicate that ER $\beta$ has no significant effect in male mice, but may restrain trabecular bone mineralization that is dependent on ER $\alpha$ in female mice.

In summary, testosterone conversion to estrogen in human males is important for both normal cortical bone development and preservation of healthy bone metabolism during aging that likely reduces fractures.

Reproduction. Although only a few men with aromatase gene mutation have been studied, these individuals consistently show oligospermia and at least one presented with infertility (24). These reproductive abnormalities may reflect the loss of estrogen production in testicular Leydig cells. Severely decreased sperm motility was also noted in the man with mutated ER $\alpha$ and in ER $\alpha$ genetically deleted male mice $(6,8)$, suggesting that signaling via $\mathrm{ER} \alpha$ regulates spermatogenesis. These findings are supported by more recent mouse studies, wherein loss of membrane or nuclear $\mathrm{ER} \alpha$ in the testes results in abnormal sperm production and function, leading to infertility as the male mice advance in age (25). Mechanistically, loss of ER $\alpha$ results in excessive fluid accumulation in the epididymis, which may contribute to abnormal sperm morphology and function (26).

In contrast to male $\mathrm{ER} \alpha \mathrm{KO}$ mice, male mice with $\mathrm{KO}$ of $\mathrm{ER} \beta$ retain relatively normal fertility in two different models $(18,19)$. Surprisingly, however, a small number of male humans with mutations in ER $\beta$ are associated with 46, XY disorders of sex development, showing markedly abnormal or absent gonads (27). These differences between mice and men with mutated or no ER $\beta$ highlight the importance of studying estrogen signaling in both mouse models and human patients.

Interestingly, a gain-of-function mutation of the aromatase gene CYP19A1, which causes increased levels of the estrogen estrone, is linked to familial gynecomastia in young males (28). This perturbation of the normal ratio of testosterone to estrogen in men underlies most forms of gynecomastia.

Additional studies suggest that estrogen contributes to libido and sexual performance in men. For example, 202 healthy men given an analogue of gonadotropin-releasing hormone ( $\mathrm{GnRH}$ ) to inhibit endogenous androgen production had loss of sexual drive and erectile function. These men then received testosterone replacement without or with an aromatase inhibitor (anastrozole) for 16 weeks. Although testosterone administration significantly improved these functions, addition of the aromatase inhibitor attenuated improvement in both libido and penile erections (29).

It is well recognized that nitric oxide (NO) formation in penile blood vessels is necessary for vasodilation and erection (30). Estrogen acting at both $\mathrm{ER} \alpha$ and $\mathrm{ER} \beta$ strongly stimulates several isoforms of the NO synthase enzyme to produce NO in endothelial and other vascular cells (31-33), which may explain the erectile dysfunction associated with loss of estradiol production from testosterone. Once NO production is impaired from penile arterial disease, such as in diabetes, perhaps estrogen can no longer 
promote vasodilation, as the sex steroid appears to prevent early arterial disease in mouse models. Thus, estradiol in men functions both in the brain (libido) and the gonads (erection) to modulate male reproduction.

CNS. Studies in animals and in humans have demonstrated that estrogen's actions in the CNS play critical roles in aggression and in sexual behavior in males, most likely due to local production of estradiol by aromatase. For example, treatment of macaques with aromatase inhibitors leads to decreased sexual motivation and ejaculatory actions (34). Human males with aromatase mutations have decreased libido and reduced sexual behavior, despite high testosterone levels, and estrogen treatment enhances libido and sexual activity (35). Similarly, as mentioned, testosterone replacement in the presence of an aromatase inhibitor in hypogonadal males leads to only a partial decrease in sexual function compared with testosterone replacement alone (29). Interestingly, aromatase expression is abundant in numerous brain nuclei of both females and males $(36,37)$, and local estradiol production in these regions appears to be critical in mediating aggressive and sexual behaviors. For example, mouse models of aromatase deficiency have shown that its actions in the hypothalamus and amygdala are important for male aggression $(38,39)$. Furthermore, male mice lacking AR expression in the CNS still exhibit male sexual and territorial actions (40), indicating that aromatization of androgens to estrogens, followed by estrogen actions on ERs, plays an essential role in what are commonly thought to be "male" behaviors.

Finally, estrogen may play a critical role in male brains beyond its actions in sexual and aggressive behavior. Local production of estradiol in the male cerebellum appears to be important for vestibular-ocular reflex adaptation (41), which coordinates eye and head movements to help stabilize vision. Estrogen also enhances spatial memory in females via hippocampus ER $\alpha$, but through ER $\beta$ in the hippocampus of male mice (42). These studies indicate that estrogen production and actions in the CNS are diverse and that more estrogen-mediated processes will likely be discovered.

Fat and the metabolic syndrome. Men with aromatase mutations often display low HDL cholesterol, high LDL cholesterol, increased triglycerides and visceral fat, and impaired glucose homeostasis $(8,24)$. These lipid abnormalities are reversed by treatment with estrogen (8). Aromatase-deficient men and the previously discussed individual with an ER $\alpha$ mutation show reduced endothelial function and premature atherosclerosis, including plaque formation. Estrogen replacement resolved these conditions in one individual (24). The hepatic steatosis reported in several of these men may be the result of elevated triglycerides (24).

Increased visceral fat has been noted in many of the men with aromatase or $\mathrm{ER} \alpha$ mutations, as well as in young men who received $\mathrm{GnRH}$ agonists to prevent testosterone synthesis. In the latter group, testosterone supplementation promoted increased muscle mass and diminished body fat development, but inhibition of visceral fat formation was not seen when testosterone and the aromatase inhibitor anastrazole together were given, suggesting that estrogen mediates this outcome (29). Estrogen inhibits visceral fat formation in mammals in several ways. Most notably, in mice, estrogen through ER $\alpha$ suppresses pluripotent stem cell commitment to the adipocyte lineage (43). Because aromatase actions in adipose tissue are the major source of circulating estrogen in men, it appears that local estrogen signaling in adipocytes may play a major role in modulating its own production (44). Estrogen may also directly affect weight and fat formation by regulating energy intake and output. In genetic mouse models, loss of ER $\alpha$ from specific hypothalamic regions results in excessive food intake and decreased energy expenditure (45). Furthermore, studies in $\mathrm{ER} \alpha$-deficient mice demonstrate that estrogen enhances insulin action in the liver, muscle, and fat of both males and females (46).

In addition to regulating insulin signaling, estrogens also modulate $\beta$ cell function in the pancreas. $E R \alpha$ in pancreatic islets suppresses fatty acid synthesis via STAT3-mediated suppression of the fatty acid synthase gene in male rats, contributing to the prevention of $\beta$ cell failure (47). In both sexes of aromatase-genedeficient mice given streptozotocin (which causes $\beta$ cell apoptosis), estrogen/ER $\alpha$ sustains insulin secretion by mitigating $\beta$ cell death (48). Nuclear ER $\alpha$ in the CNS helps to maintain insulin sensitivity in female mice, while loss of nuclear ER $\alpha$ impairs the ability of glucose injected into the carotid artery to stimulate brain regulation of insulin secretion only in male mice (49). These findings indicate roles for ER $\alpha$ to positively regulate normal glucose homeostasis in both male and female mice. This is consistent with impaired glucose homeostasis in men with aromatase gene mutations $(9,11)$. However, both in ER $\alpha$ deletion models in mice and the aforementioned male humans, there is no evidence of diabetes, indicating a moderate regulatory role for the sex steroid receptor.

Aromatase-deficient men and the ER $\alpha$ mutant male also showed indications of the metabolic syndrome, including hypertension. Estrogen administration reversed many of these disorders, including improvements in insulin resistance and glucose intolerance (24). Interestingly, ER $\beta-\mathrm{KO}$ male and female mice (specifically C-ER $\beta-\mathrm{KO}$ ) become hypertensive with aging (32), suggesting that this ER isoform may also contribute to normalization of blood pressure. In mice, deletion of ER $\alpha$ confined to adipocytes resulted in increased markers of fibrosis and inflammation in the fat niche, as well as impaired overall glucose homeostasis, effects that were more pronounced in males (50).

In summary, various aspects of the metabolic syndrome are clearly improved in male mouse models of disease, but, while suggestive, whether this extends to men requires additional determination.

Prostate cancer. In the normal human prostate, both ER $\alpha$ and ER $\beta$ are expressed mainly in the stroma and epithelium, respectively (51). ER $\alpha$ is generally felt to be proproliferative in normal and malignant prostate, contributing to the development of premalignant lesions and cancer in rodent models. In contrast, ER $\beta$ maintains epithelial differentiation while inhibiting proliferation caused by $\mathrm{ER} \alpha$, thereby promoting normal development and at least initially acting as a suppressor of prostate cancer development. A synthetic estrogen, diethylstilbestrol (DES), was used to successfully treat prostate cancer in the 1960s and 1970s, suppressing androgen production through feedback upon the hypothalamic-pituitary axis (52). However, due to its prothrombotic effects, a high number of myocardial infarctions resulted in DES-treated patients. Nevertheless, these studies suggested targeting ER in prostate cancer could be therapeutically advantageous.

Clinical trials using an ER $\alpha$ agonist (53) or a selective ER modulator (54) have not generated sufficiently impactful evidence for the treatment of prostate cancer to justify comprehensive 
studies in this malignancy. This may reflect the complexity of the nuclear ER working in conjunction with the nuclear AR in myriad ways, depending upon the stage of the tumor. In addition, there are various ER $\beta$ isoforms that have either tumor-suppressive or tumor-promoting functions (55). ER $\beta$ isoform switching has been observed in castration-resistant and metastatic prostate cancer in men, perhaps explaining the dichotomy of $\operatorname{ER} \beta$ actions in various types of this malignancy. Interestingly, recent studies in humans show that a high expression of ER $\beta$ occurs in many prostate cancers and correlates to a favorable prognosis (56), whereas high levels of estradiol or estrone are significantly associated with a shorter time to the development of castration-resistant prostate cancer, presumably through actions at $\mathrm{ER} \alpha$ (57). In aromatase-KO mice, an ER $\beta$ agonist induces apoptosis of stromal, luminal, and epithelial cells within the prostate. Agonists for this receptor also induce apoptosis in stroma and epithelial progenitor cells using patient-derived, Gleason-7 xenograft tissues in mice. This process is mediated by TNF- $\alpha$-mediated upregulation of caspase- 8 (58). Realizing the importance of ER in the prostate, interventional paradigms continue to be developed.

\section{Androgen action in women}

Preface. While estrogens are considered the dominant sex steroid in women, in fact, serum androgen levels in women are higher than estrogen levels most of the time. The exception is during the preovulatory and midluteal phases of the menstrual cycle, when androgen and estrogen levels are similar. Therefore, it is reasonable to consider that androgens might have important physiologic effects in women. However, there are many difficulties relating androgen levels to physiological or disease processes, primarily due to unknowns about steroid metabolism and inefficiencies in accurately measuring testosterone levels. With regard to steroid metabolism, most androgen actions are likely mediated by intracellular conversion to DHT; thus, it is unclear whether serum testosterone levels truly reflect active androgen levels. In addition, testosterone is readily converted to $\mathrm{E} 2$ by aromatase in most tissues; therefore, observations associated with high testosterone levels might really reflect estrogen actions.

Even more troubling is determining how to measure testosterone. First, most testosterone immunoassays are inaccurate below approximately $100 \mathrm{ng} / \mathrm{ml}$, which is where testosterone levels in women rest. In fact, even in hypogonadal men with testosterone levels in the 100-200 $\mathrm{ng} / \mathrm{ml}$ range, immunoassays are not accurate. Second, it is unclear which testosterone moiety should be measured. More than $98 \%$ of testosterone is bound to proteins, either tightly to sex hormone-binding globulin (SHBG) (about 66\%) or weakly to other proteins such as albumin (about $33 \%$ ) (59). Therefore, it is not clear which measurement (total testosterone, free testosterone, or bioavailable testosterone- nonSHBG-bound) is most meaningful. The answer is still not known; however, the Endocrine Society suggests that total testosterone measured by liquid chromatography/mass spectroscopy in a qualified laboratory is most useful, although other validated assays may be appropriate in some instances $(60,61)$.

Bone development and function. In humans, the role of testosterone in female bone formation is still not well understood. As mentioned, it is clear that the majority of testosterone's effects in the bone depends on its aromatase-mediated conversion to estradiol. However, men still have bigger bones, suggesting that androgens may play an independent role in regulating bone size. Data from humans and mouse models suggest that androgens enhance bone size by maintaining cancellous (trabecular) bone mass (62). Rodent models also suggest that androgens enhance bone size by promoting periosteal bone apposition (63). However, in one aromatase-deficient human male with high testosterone levels, quantitative CT demonstrated decreased periosteal bone apposition that improved upon estradiol therapy (11); thus, the role of androgens versus estrogens in human periosteal bone apposition is still not clearly defined. Notably, individuals with complete androgen insensitivity (e.g., XY individuals with inactivating mutations in ARs) have decreased bone size and density (including trabecular bone) relative to both normal males and females, yet have no increase in fracture rate (64). Accordingly, in AR-KO male mice, cancellous/trabecular bone volumes are smaller and less dense, even though androgen and estradiol levels are normal (65). Similarly, in male mice, specific inactivation of the AR in bone-forming osteoblasts confers no change in cortical bone, but a significant reduction in trabecular bone volume (66), again suggesting that androgens maintain trabecular/cancellous bone mass. AR deficiency has less dramatic effects on the bones of female mice, but these mice still display reduced cortical bone mass and significantly altered cancellous bone architecture $(66,67)$. These observations indicate that, in females, androgens may have estrogenindependent effects on bone metabolism and growth via the AR.

Reproduction. It is established that androgens are important in female reproduction. For example, the most common cause of infertility in women is polycystic ovary syndrome (PCOS), which is characterized by androgen excess, oligomenorrhea or amenorrhea, and polycystic ovaries. While two out of these three are sufficient for diagnosis, the majority of PCOS patients have androgen excess and ovulatory dysfunction, and androgens are thought to be a critical mediator of the reproductive dysfunction (68). The pathophysiology is unclear, but in part, it involves a powerful positive feedback loop whereby ovarian androgens increase the frequency of hypothalamic GnRH pulsations. This activity favors pituitary LH over FSH secretion, resulting in the loss of an estradiol and subsequent LH surge, leading to anovulation and even more ovarian androgen production $(69,70)$. In addition, excess androgens have direct effects on the ovary, perhaps promoting increased or unregulated follicle growth, which then prevents normal selection of a single follicle for ovulation (71). In fact, $\mathrm{KO}$ of the AR in mouse follicular theca cells slightly protects cycling in hyperandrogenic mice (72), suggesting that AR signaling in theca cells may partially drive the abnormal reproductive phenotype seen in PCOS.

Whereas androgen excess clearly impairs female fertility, physiologic androgen levels play a positive role. For many years, work in vitro and in animal models suggested that androgens might play an important role in follicle growth, perhaps acting to enhance FSH-mediated signaling $(73,74)$. Proof of this concept came with the description of a female mouse in which the AR was specifically ablated in ovarian granulosa cells (75). These mice have decreased ovulation rates, smaller litter sizes, and premature ovarian failure, primarily due to the loss of AR-mediated signals that prevent follicle atresia and augment FSH-mediated follicle 

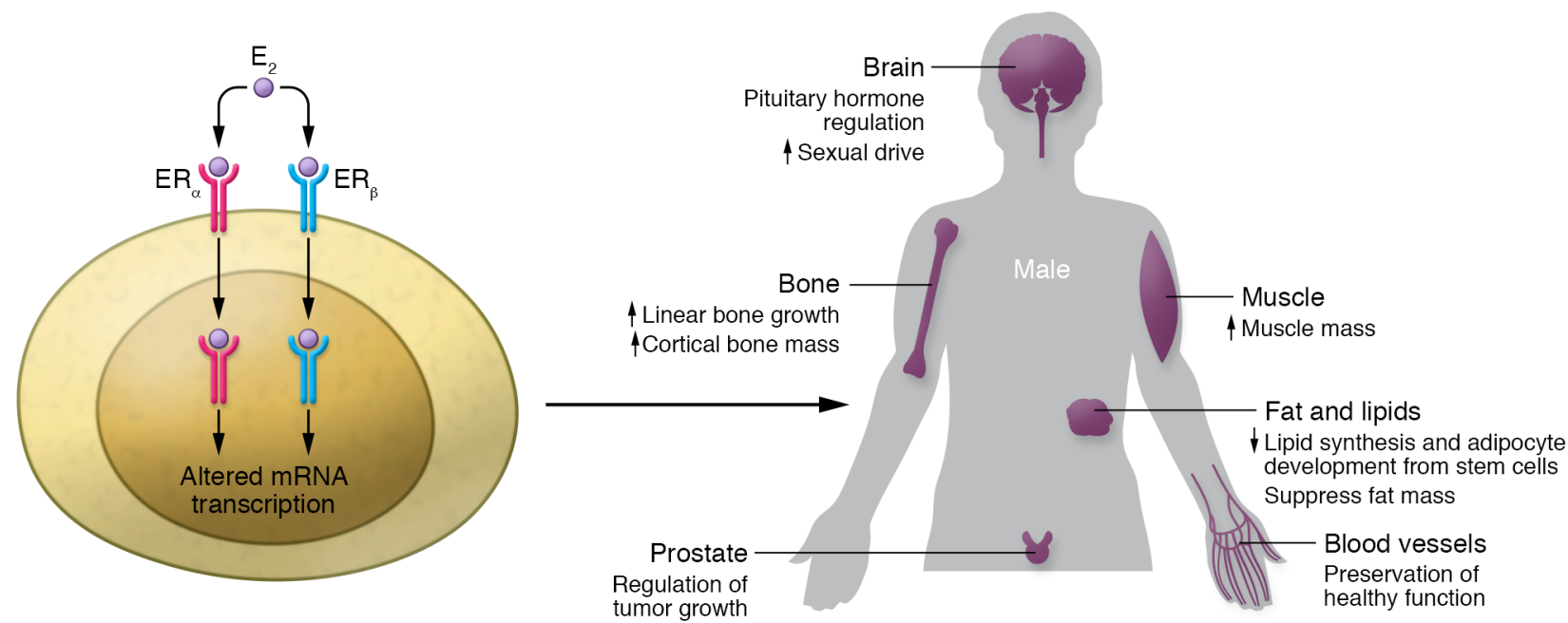

Figure 1. Estrogens act through ER $\alpha$ and ERß at the plasma membrane and in the nucleus to regulate functions of many organs in men. Estrogen inhibits excessive fat cell development and lipid synthesis in adipocytes and hepatocytes, thereby contributing to metabolic health. Estrogen stimulation of bone or blood vessel cell functions preserves the integrity of the organ, preventing disease. In pathological states, such as prostate cancer, complicated actions mediated through different ER isoforms underlie both stimulating and suppressing actions in the various cells that make up the tumor.

growth (76). These findings in mice are consistent with observations in women with diminished ovarian reserve, in whom studies suggest that androgen pretreatment improves fertilization rates (77). The human studies are small and not always well controlled; thus, larger randomized placebo-controlled studies are necessary. However, the concept that a tightly balanced androgen milieu in the ovary is necessary for normal fertility is now well established.

Androgens may also play a role in the maintenance of pregnancy, especially with regard to parturition. Total testosterone levels reportedly increase slightly during pregnancy (78); however, due to the use of less accurate immunoassays, along with increased SHBG production during pregnancy, it is unclear whether free testosterone levels change during pregnancy. In contrast, androgen levels are higher in pregnant women with PCOS, with a reported increase in the incidence of preterm labor (79). Treatment of female primates with the androgen androstenedione triggers premature uterine contractions in some but not all studies (80, 81). Animal models support a potential role for androgen in parturition, as androgen actions through the AR promote collagenase expression in the cervix, leading to cervical remodeling critical for normal delivery $(82,83)$. In animals and in humans, AR levels are high in myometrial cells early in pregnancy but are reduced by parturition $(84,85)$. Studies in rodents suggest that androgen signaling via the AR suppresses myometrial contractility by modulating calcium signaling in a transcription-independent fashion; thus, as myometrial AR levels drop at the end of gestation, suppression of myometrial contractions may be reduced, which, in combination with the aforementioned cervical remodeling, leads to parturition (85-87). More studies on androgen actions during pregnancy are needed; however, combined with the studies on ovarian function, androgens appear important for female reproduction from follicle development through parturition.

CNS. Like estradiol, testosterone levels in women decrease with age, although postmenopausal serum testosterone levels drop only 2-fold, while estradiol levels drop 10-fold (88). Nonetheless, this decrease in testosterone has been implicated in postmenopausal decreases in libido, and possibly to hypoactive sexual desire disorder (HSDD), defined as a deficiency of sexual fantasies and desire for normal sexual activity that causes significant stress or interpersonal difficulty (89). In general, some studies suggest a correlation between serum testosterone levels and sexual desire $(90,91)$, but others do not $(92,93)$. These discrepancies may in part be related to the varying methods used to measure testosterone; thus, to date, no clear evidence exists that definitively relates androgen levels to sexual desire. Several randomized placebocontrolled studies have suggested that androgen treatment (either testosterone or dehydroepiandrosterone [DHEA]) improves sexual desire and performance $(94,95)$ independently of androgen levels, especially in HSDD $(96,97)$. However, most of these studies are small, demonstrate large placebo effects, and are based on surveys rather than concrete quantitative measurements.

After careful examination of the available data, the recommendations of the Endocrine Society are against making a diagnosis of androgen deficiency in women (98). Furthermore, the Society recommends against prescribing testosterone for women except those with HSDD. Notably, such replacement medications are not available in many countries, including the United States, and long-term safety data are not known. Care with monitoring for signs of androgen excess (e.g., hirsutism, acne, thinning of scalp hair) should be taken, and testosterone should be stopped if no significant improvement is seen.

Fat and the metabolic syndrome. As mentioned, women with PCOS have androgen excess and reduced fertility. In addition, PCOS is closely linked with obesity, insulin resistance, and the metabolic syndrome. Studies suggest that obesity, insulin resistance, and subsequent hyperinsulinemia lead to androgen excess, perhaps in part via selective insulin sensitivity in the ovaries that results in excessive insulin-mediated androgen production (99, 100). However, androgen treatment of mice and rats can also promote weight gain and insulin resistance in female mice, ulti- 

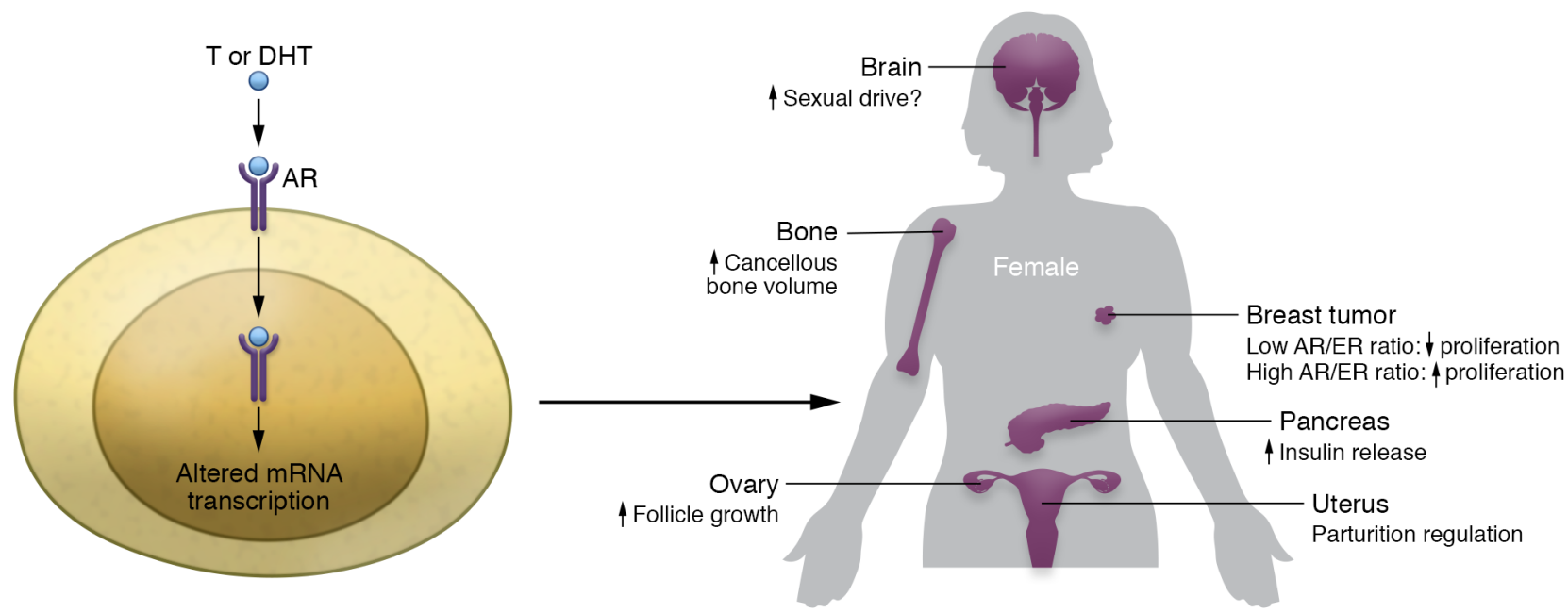

Figure 2. Androgens (including testosterone [T] and DHT) act through AR at the plasma membrane and in the nucleus to regulate many functions in women. In the brain, androgens may improve sexual desire and performance, most notably in women with HSDD. In bone, androgens regulate bone size, perhaps by controlling cancellous bone volume. In the uterus, androgens may regulate parturition by modifying myometrial contractility and cervical remodeling. In the ovary, at physiologic concentrations, androgens promote normal follicular development, though high concentrations of androgens dysregulate follicle development. In breast, androgens have little effect on normal mammary development. In breast cancer, however, androgens may suppress growth when the ratio of AR/ER $\alpha$ signaling is low, but may promote growth when AR/ER $\alpha$ signaling is high. Finally, in the pancreas, androgens may promote insulin release

mately leading to hyperglycemia. This androgen-induced phenomenon is substantially attenuated in female mice with the AR knocked out specifically in $\beta$ cells (101), suggesting a positive feedback loop whereby, in PCOS, insulin from $\beta$ cells promotes ovarian androgen production, which in turn stimulates more insulin production by the $\beta$ cell.

Breast cancer. The role of ARs in breast cancer has been discussed for years but has recently returned to the limelight. ARs are expressed in many different breast cell types, and androgens have long been considered "stop" signals during normal estrogen- and progesterone-mediated breast development, which might explain why men do not develop breasts unless testosterone levels are low. AR signaling, however, may only be a minor contributor to normal breast development, as global AR null female mice have subtle to no changes in their mammary glands (65). With regard to breast cancer, up to $90 \%$ of tumors express ARs. In general, AR expression is considered a positive prognostic factor for breast cancer, especially when tumors are both ER $\alpha$ and AR positive (102-104). Accordingly, androgens were once used to treat breast cancer, with general efficacy in blocking cancer progression (105, 106). These observations are consistent with postulated antiproliferative effects of androgens on normal breast development. In contrast, only $50 \%$ of ER $\alpha$-negative breast cancers express ARs, and AR expression seems to have a neutral to possibly negative effect on prognosis $(102,107)$. Finally, approximately $30 \%$ of triple-negative breast cancers (ER $\alpha, P R$, and ERB2/Her2 negative) are AR positive, and AR expression again predicts a neutral to worse outcome (108-110). In vitro studies suggest that AR signaling suppresses growth in ER $\alpha$-positive breast cancer cells but promotes growth in ER $\alpha$-negative cells. Even in the presence of ER $\alpha$, if AR is overexpressed, or if breast cancer cells become resistant to tamoxifen suppression, androgens become promoters of proliferation $(111,112)$. These studies suggest a complex crosstalk between
AR and ER $\alpha$ signaling $(113,114)$ whereby the higher the ratio of AR to ER, either in terms of levels or activities, the more sensitive cells become to AR-mediated growth. Interestingly, antiandrogen treatment of $\mathrm{ER}^{+} / \mathrm{AR}^{+}$breast cancer cell lines reduces ER-mediated proliferation both in vitro and in xenograft models (115), again indicating a complex crosstalk between AR and ER signaling. Furthermore, AR/HER2 crosstalk has been reported: antiandrogen treatment suppresses HER2 phosphorylation and activation in vitro, and combined antiandrogen/anti-HER2 suppresses xenograft growth more than either treatment individually $(116,117)$.

Clinically, a phase II clinical trial using the AR antagonist bicalutamide to treat $\mathrm{ER} \alpha$ /progesterone-receptor-negative tumors demonstrates a 19\% clinical benefit rate (progression-free survival) over 6 months (118). A second phase II clinical trial using the more potent anti-AR drug enzalutamide in $\mathrm{AR}^{+}$, triple-negative tumors demonstrates a similar $25 \%$ clinical benefit rate at 16 weeks (119). Finally, a phase II trial using the CYP17 inhibitor abiraterone, which suppresses androgen production, in $\mathrm{AR}^{+}$, triple-negative breast cancer demonstrates a similar 6-month clinical benefit rate of $20 \%$ (120). Thus, antiandrogen treatment holds promise for the treatment of triple-negative breast cancer, though randomized placebo-controlled studies are needed to truly address their benefit.

\section{Conclusions}

In summary, significant evidence demonstrates that estrogens and androgens play important roles in male and female biology, respectively (Figures 1 and 2). This may include effects in the CNS and bone as well as in the reproductive and cardiovascular systems. While abundant evidence has been shown in rodent models, conclusive evidence in humans has not yet been established. One pattern that appears to be present in many tissues in both women and men is that estrogen signaling through ERs and androgen signaling through ARs are always important; however, 
the physiologic response can vary tremendously depending on the ratio of ER/AR signaling, as well as the amount of steroid metabolism occurring locally. Together, the examples presented here, as well as many others, suggest that traditional views whereby sexual dimorphisms between women and men are explained almost exclusively by the presence of estrogens in women and androgens in men must be modified to reflect the complexities of steroid hormone signaling and biology.
Address correspondence to: Stephen R. Hammes, Division of Endocrinology and Metabolism, Department of Medicine, University of Rochester School of Medicine, 601 Elmwood Avenue, Rochester, New York 14642, USA. Phone: 585.275.2901; Email: stephen_hammes@urmc.rochester.edu. Or to: Ellis R. Levin, Medical Service (111-I), Long Beach Veterans Affairs Medical Center, 5901 East 7th Street, Long Beach, California 90822, USA. Phone: 562.826.8000, ext. 24147; Email: ellis.levin@va.gov.
1. Jensen EV, Desombre ER, Kawashima T, Suzuki T, Kyser K, Jungblut PW. Estrogen-binding substances of target tissues. Science. 1967;158(3800):529-530.

2. Kuiper GG, Enmark E, Pelto-Huikko M, Nilsson S, Gustafsson JA. Cloning of a novel receptor expressed in rat prostate and ovary. Proc Natl Acad Sci U S A. 1996;93(12):5925-5930.

3. Franchimont P. Regulation of gonadal androgen secretion. Horm Res. 1983;18(1-3):7-17.

4. Harada N. Cloning of a complete cDNA encoding human aromatase: immunochemical identification and sequence analysis. Biochem Biophys Res Commun. 1988;156(2):725-732.

5. Jones ME, Boon WC, McInnes K, Maffei L, Carani C, Simpson ER. Recognizing rare disorders: aromatase deficiency. Nat Clin Pract Endocrinol Metab. 2007;3(5):414-421.

6. Smith EP, et al. Estrogen resistance caused by a mutation in the estrogen-receptor gene in a man. N Engl J Med. 1994;331(16):1056-1061.

7. Rochira V, et al. Hypothalamic-pituitary-gonadal axis in two men with aromatase deficiency: evidence that circulating estrogens are required at the hypothalamic level for the integrity of gonadotropin negative feedback. Eur J Endocrinol. 2006;155(4):513-522.

8. Carani C, et al. Effect of testosterone and estradiol in a man with aromatase deficiency. $N$ EnglJ Med.1997;337(2):91-95.

9. Miedlich SU, Karamooz N, Hammes SR. Aromatase deficiency in a male patient - Case report and review of the literature. Bone. 2016;93:181-186.

10. Lindzey J, Wetsel WC, Couse JF, Stoker T, Cooper $\mathrm{R}$, Korach KS. Effects of castration and chronic steroid treatments on hypothalamic gonadotropin-releasing hormone content and pituitary gonadotropins in male wild-type and estrogen receptor-alpha knockout mice. Endocrinology. 1998;139(10):4092-4101.

11. Bouillon R, Bex M, Vanderschueren D, Boonen S. Estrogens are essential for male pubertal periosteal bone expansion. JClin Endocrinol Metab. 2004;89(12):6025-6029.

12. Falahati-Nini A, Riggs BL, Atkinson EJ, O'Fallon WM, Eastell R, Khosla S. Relative contributions of testosterone and estrogen in regulating bone resorption and formation in normal elderly men. JClin Invest. 2000;106(12):1553-1560.

13. Leder BZ, Rohrer JL, Rubin SD, Gallo J, Longcope C. Effects of aromatase inhibition in elderly men with low or borderline-low serum testosterone levels. JClin Endocrinol Metab. 2004;89(3):1174-1180.

14. Roggia $C$, et al. Up-regulation of TNF-producing $\mathrm{T}$ cells in the bone marrow: a key mech- anism by which estrogen deficiency induces bone loss in vivo. Proc Natl Acad Sci U S A. 2001;98(24):13960-13965.

15. Charatcharoenwitthaya N, Khosla S, Atkinson EJ, McCready LK, Riggs BL. Effect of blockade of TNF- $\alpha$ and interleukin- 1 action on bone resorption in early postmenopausal women. J Bone Miner Res. 2007;22(5):724-729.

16. Eghbali-Fatourechi G, Khosla S, Sanyal A, Boyle WJ, Lacey DL, Riggs BL. Role of RANK ligand in mediating increased bone resorption in early postmenopausal women.J Clin Invest. 2003;111(8):1221-1230.

17. Khosla S. New insights into androgen and estrogen receptor regulation of the male skeleton. J Bone Miner Res. 2015;30 (7):1134-1137.

18. Krege JH, et al. Generation and reproductive phenotypes of mice lacking estrogen receptor beta. Proc Natl Acad Sci U S A. 1998;95(26):15677-15682.

19. Dupont S, Krust A, Gansmuller A, Dierich A, Chambon P, Mark M. Effect of single and compound knockouts of estrogen receptors alpha $(\mathrm{ER} \alpha)$ and beta (ER $\beta)$ on mouse reproductive phenotypes. Development. 2000;127(19):4277-4291.

20. Windahl SH, Vidal O, Andersson G, Gustafsson JA, Ohlsson C. Increased cortical bone mineral content but unchanged trabecular bone mineral density in female ER $\beta(-/-)$ mice. JClin Invest. 1999;104(7):895-901.

21. Windahl SH, Hollberg K, Vidal O, Gustafsson JA, Ohlsson C, Andersson G. Female estrogen receptor $\beta^{-/-}$mice are partially protected against age-related trabecular bone loss. J Bone Miner Res. 2001;16(8):1388-1398.

22. Sims NA, et al. Deletion of estrogen receptors reveals a regulatory role for estrogen receptors $-\beta$ in bone remodeling in females but not in males. Bone. 2002;30(1):18-25.

23. Nicks KM, et al. Deletion of estrogen receptor $\beta$ in osteoprogenitor cells increases trabecular but not cortical bone mass in female mice. J Bone Miner Res. 2016;31(3):606-614.

24. Jones ME, Boon WC, Proietto J, Simpson ER. Of mice and men: the evolving phenotype of aromatase deficiency. Trends Endocrinol Metab. 2006;17(2):55-64.

25. Nanjappa MK, Hess RA, Medrano TI, Locker SH, Levin ER, Cooke PS. Membrane-localized estrogen receptor 1 is required for normal male reproductive development and function in mice. Endocrinology. 2016;157(7):2909-2919.

26. Joseph A, Shur BD, Ko C, Chambon P, Hess RA. Epididymal hypo-osmolality induces abnormal sperm morphology and function in the estrogen receptor $\alpha$ knockout mouse. Biol Reprod.

\section{0;82(5):958-967.}

27. Baetens D, et al. Biallelic and monoallelic ESR2 variants associated with $46, \mathrm{XY}$ disorders of sex development. Genet Med.2018;20(7):717-727.

28. Shozu M, et al. Estrogen excess associated with novel gain-of-function mutations affecting the aromatase gene. N Engl JMed. 2003;348(19):1855-1865.

29. Finkelstein JS, et al. Gonadal steroids and body composition, strength, and sexual function in men. N Engl J Med. 2013;369(11):1011-1022.

30. Simonsen U, García-Sacristán A, Prieto D. Penile arteries and erection. J Vasc Res. 2002;39(4):283-303.

31. Ishikawa T, et al. LXR $\beta /$ estrogen receptor- $\alpha$ signaling in lipid rafts preserves endothelial integrity. J Clin Invest. 2013;123(8):3488-3497.

32. Zhu Y, et al. Abnormal vascular function and hypertension in mice deficient in estrogen receptor $\beta$. Science. 2002;295(5554):505-508.

33. Pedram A, Razandi M, Blumberg B, Levin ER. Membrane and nuclear estrogen receptor $\alpha$ collaborate to suppress adipogenesis but not triglyceride content. FASEB J. 2016;30(1):230-240.

34. Zumpe D, Bonsall RW, Michael RP. Effects of the nonsteroidal aromatase inhibitor, fadrozole, on the sexual behavior of male cynomolgus monkeys (Macaca fascicularis). Horm Behav. 1993;27(2):200-215.

35. Carani C, Rochira V, Faustini-Fustini M, Balestrieri A, Granata AR. Role of oestrogen in male sexual behaviour: insights from the natural model of aromatase deficiency. Clin Endocrinol (Oxf). 1999;51(4):517-524.

36. Roselli CF. Brain aromatase: roles in reproduction and neuroprotection. J Steroid Biochem Mol Biol. 2007;106(1-5):143-150.

37. Sasano H, Takashashi K, Satoh F, Nagura $\mathrm{H}$, Harada N. Aromatase in the human central nervous system. Clin Endocrinol (Oxf). 1998;48(3):325-329.

38. Wu MV, et al. Estrogen masculinizes neural pathways and sex-specific behaviors. Cell. 2009;139(1):61-72.

39. Unger EK, Burke KJ Jr, Yang CF, Bender KJ, Fuller PM, Shah NM. Medial amygdalar aromatase neurons regulate aggression in both sexes. Cell Rep. 2015;10(4):453-462.

40. Juntti SA, et al. The androgen receptor governs the execution, but not programming, of male sexual and territorial behaviors. Neuron. 2010;66(2):260-272.

41. Dieni CV, et al. 17 $\beta$-estradiol synthesis modulates cerebellar dependent motor memory formation in adult male rats. Neurobiol Learn Mem. 2018;155:276-286. 
42. Wang W, et al. Memory-related synaptic plasticity is sexually dimorphic in rodent hippocampus. JNeurosci. 2018;38(37):7935-7951.

43. Pedram A, Razandi M, Blumberg B, Levin ER. Membrane and nuclear estrogen receptor $\alpha$ collaborate to suppress adipogenesis but not triglyceride content. FASEB J. 2016;30(1):230-240.

44. Simpson ER, et al. Aromatase cytochrome P450, the enzyme responsible for estrogen biosynthesis. Endocr Rev. 1994;15(3):342-355.

45. Xu Y, et al. Distinct hypothalamic neurons mediate estrogenic effects on energy homeostasis and reproduction. Cell Metab. 2011;14(4):453-465.

46. Ribas V, et al. Impaired oxidative metabolism and inflammation are associated with insulin resistance in ER $\alpha$-deficient mice. Am J Physiol Endocrinol Metab. 2010;298(2):E304-E319.

47. Tiano JP, et al. Estrogen receptor activation reduces lipid synthesis in pancreatic islets and prevents $\beta$ cell failure in rodent models of type 2 diabetes. J Clin Invest. 2011;121(8):3331-3342.

48. Le May C, et al. Estrogens protect pancreatic beta-cells from apoptosis and prevent insulindeficient diabetes mellitus in mice. Proc Natl Acad Sci U S A. 2006;103(24):9232-9237.

49. Allard C, et al. Loss of nuclear membrane estrogen receptor- $\alpha$ differentially impairs insulin secretion action in male female mice [published online ahead of print October 10, 2018]. Diabetes. https://doi.org/10.2337/db18-0293.

50. Davis KE, et al. The sexually dimorphic role of adipose and adipocyte estrogen receptors in modulating adipose tissue expansion, inflammation, and fibrosis. Mol Metab. 2013;2(3):227-242.

51. Nelson AW, Tilley WD, Neal DE, Carroll JS. Estrogen receptor beta in prostate cancer: friend or foe? Endocr Relat Cancer. 2014;21(4):T219-T234.

52. Bailar JC 3rd, Byar DP. Estrogen treatment for cancer of the prostate. Early results with 3 doses of diethylstilbestrol and placebo. Cancer. 1970;26(2):257-261.

53. Yu EY, et al. Selective estrogen receptor alpha agonist GTX-758 decreases testosterone with reduced side effects of androgen deprivation therapy in men with advanced prostate cancer. Eur Urol. 2015;67(2):334-341.

54. Fujimura T, et al. Toremifene, a selective estrogen receptor modulator, significantly improved biochemical recurrence in bone metastatic prostate cancer: a randomized controlled phase II a trial. BMC Cancer. 2015;15:836.

55. Leung YK, et al. Estrogen receptor $\beta 2$ and $\beta 5$ are associated with poor prognosis in prostate cancer, and promote cancer cell migration and invasion. Endocr Relat Cancer. 2010;17(3):675-689.

56. Azizan N, Hayati F, Tizen NMS, Farouk WI, Masir $\mathrm{N}$. Role of co-expression of estrogen receptor $\beta$ and Ki67 in prostate adenocarcinoma. Investig Clin Urol. 2018;59(4):232-237.

57. Toren $\mathrm{P}$, et al. Serum sex steroids as prognostic biomarkers in patients receiving androgen deprivation therapy for recurrent prostate cancer: a post hoc analysis of the PR.7 trial. Clin Cancer Res. 2018;24(21):5305-5312.

58 . McPherson SJ, et al. Estrogen receptor- $\beta$ activated apoptosis in benign hyperplasia and cancer of the prostate is androgen independent and TNFalpha mediated. Proc Natl Acad Sci U S A.
2010;107(7):3123-3128.

59. Dunn JF, Nisula BC, Rodbard D. Transport of steroid hormones: binding of 21 endogenous steroids to both testosterone-binding globulin and corticosteroid-binding globulin in human plasma. JClin Endocrinol Metab. 1981;53(1):58-68.

60. Wierman ME, et al. Editorial: The new instructions to authors for the reporting of steroid hormone measurements. JClin Endocrinol Metab. 2014;99(12):4375.

61. Handelsman DJ, Wartofsky L. Requirement for mass spectrometry sex steroid assays in the Journal of Clinical Endocrinology and Metabolism. JClin Endocrinol Metab. 2013;98(10):3971-3973.

62. Vanderschueren D, Vandenput L, Boonen S, Lindberg MK, Bouillon R, Ohlsson C. Androgens and bone. Endocr Rev. 2004;25(3):389-425.

63. Turner RT, Wakley GK, Hannon KS. Differential effects of androgens on cortical bone histomorphometry in gonadectomized male and female rats. JOrthop Res. 1990;8(4):612-617.

64. Bertelloni S, Baroncelli GI, Federico G, Cappa M, Lala R, Saggese G. Altered bone mineral density in patients with complete androgen insensitivity syndrome. Horm Res. 1998;50(6):309-314.

65. Yeh S, et al. Generation and characterization of androgen receptor knockout (ARKO) mice: an in vivo model for the study of androgen functions in selective tissues. Proc Natl Acad Sci U S A. 2002;99(21):13498-13503.

66. Määttä JA, et al. Inactivation of the androgen receptor in bone-forming cells leads to trabecular bone loss in adult female mice. Bonekey Rep. 2013;2:440.

67. MacLean HE, et al. DNA-binding-dependent androgen receptor signaling contributes to gender differences and has physiological actions in males and females. JEndocrinol. 2010;206(1):93-103.

68. Goodarzi MO, Dumesic DA, Chazenbalk G, Azziz R. Polycystic ovary syndrome: etiology, pathogenesis and diagnosis. Nat Rev Endocrinol. 2011;7(4):219-231.

69. McCartney CR, Eagleson CA, Marshall JC. Regulation of gonadotropin secretion: implications for polycystic ovary syndrome. Semin Reprod Med. 2002;20(4):317-326.

70. Eagleson CA, et al. Polycystic ovarian syndrome: evidence that flutamide restores sensitivity of the gonadotropin-releasing hormone pulse generator to inhibition by estradiol and progesterone. J Clin Endocrinol Metab. 2000;85(11):4047-4052.

71. Vendola KA, Zhou J, Adesanya OO, Weil SJ, Bondy CA. Androgens stimulate early stages of follicular growth in the primate ovary. JClin Invest. 1998;101(12):2622-2629.

72. Ma Y, et al. Androgen receptor in the ovary theca cells plays a critical role in androgeninduced reproductive dysfunction. Endocrinology. 2017;158(1):98-108.

73. Weil S, Vendola K, Zhou J, Bondy CA. Androgen and follicle-stimulating hormone interactions in primate ovarian follicle development. JClin Endocrinol Metab. 1999;84(8):2951-2956.

74. Hillier SG, de Zwart FA. Androgen/antiandrogen modulation of cyclic AMP-induced steroidogenesis during granulosa cell differentiation in tissue culture. Mol Cell Endocrinol. 1982;28(3):347-361.

75. Sen A, Hammes SR. Granulosa cell-specific androgen receptors are critical regulators of ovarian development and function. Mol Endocrinol. 2010;24(7):1393-1403.

76. Sen A, et al. Androgens regulate ovarian follicular development by increasing follicle stimulating hormone receptor and microRNA-125b expression. Proc Natl Acad Sci U S A. 2014;111(8):3008-3013.

77. Sunkara SK, Coomarasamy A. Androgen pretreatment in poor responders undergoing controlled ovarian stimulation and in vitro fertilization treatment. Fertil Steril. 2011;95(8):e73-e75.

78. O'Leary P, Boyne P, Flett P, Beilby J, James I. Longitudinal assessment of changes in reproductive hormones during normal pregnancy. Clin Chem. 1991;37(5):667-672.

79. Yamamoto M, et al. Risk of preterm delivery in non-diabetic women with polycystic ovarian syndrome. J Perinatol. 2012;32(10):770-776.

80. Figueroa JP, Honnebier MB, Binienda Z, Wimsatt J, Nathanielsz PW. Effect of a 48-hour intravenous delta 4 -androstenedione infusion on the pregnant rhesus monkey in the last third of gestation: changes in maternal plasma estradiol concentrations and myometrial contractility. Am JObstet Gynecol. 1989;161(2):481-486.

81. Mecenas CA, et al. Production of premature delivery in pregnant rhesus monkeys by androstenedione infusion. Nat Med.1996;2(4):443-448.

82. Mahendroo MS, Porter A, Russell DW, Word RA. The parturition defect in steroid $5 \alpha$-reductase type 1 knockout mice is due to impaired cervical ripening. Mol Endocrinol. 1999;13(6):981-992.

83. Ji H, Dailey TL, Long V, Chien EK. Androgen-regulated cervical ripening: a structural, biomechanical, and molecular analysis. Am JObstet Gynecol. 2008;198(5):543.e1-543.e9.

84. Bethin KE, et al. Microarray analysis of uterine gene expression in mouse and human pregnancy. Mol Endocrinol. 2003;17(8):1454-1469.

85. Słomczyńska M, Duda M, Burek M, Knapczyk K, Czaplicki D, Koziorowski M. Distribution of androgen receptor in the porcine uterus throughout pregnancy. Reprod Domest Anim. 2008;43(1):35-41.

86. Perusquía M, Navarrete E, Jasso-Kamel J, Montaño LM. Androgens induce relaxation of contractile activity in pregnant human myometrium at term: a nongenomic action on L-type calcium channels. Biol Reprod. 2005;73(2):214-221.

87. Liu L, et al. Proliferative action of the androgen receptor in human uterine myometrial cells - a key regulator for myometrium phenotype programming. JClin Endocrinol Metab. 2013;98(1):218-227.

88. Rothman MS, et al. Reexamination of testosterone, dihydrotestosterone, estradiol and estrone levels across the menstrual cycle and in postmenopausal women measured by liquid chromatography-tandem mass spectrometry. Steroids. 2011;76(1-2):177-182.

89. Rosen RC, Maserejian NN, Connor MK, Krychman ML, Brown CS, Goldstein I. Characteristics of premenopausal and postmenopausal women with acquired, generalized hypoactive sexual desire disorder: the Hypoactive Sexual Desire Disorder Registry for women. Menopause. 2012;19(4):396-405.

90. Bachmann G, et al. Female androgen insufficien- 
cy: the Princeton consensus statement on definition, classification, and assessment. Fertil Steril. 2002;77(4):660-665.

91. Wåhlin-Jacobsen S, et al. Is there a correlation between androgens and sexual desire in women? J Sex Med. 2015;12(2):358-373.

92. Dennerstein L, Lehert P, Burger H. The relative effects of hormones and relationship factors on sexual function of women through the natural menopausal transition. Fertil Steril. 2005;84(1):174-180.

93. Santoro N, et al. Correlates of circulating androgens in mid-life women: the study of women's health across the nation. JClin Endocrinol Metab. 2005;90(8):4836-4845.

94. Davis SR, et al. Testosterone for low libido in postmenopausal women not taking estrogen. N Engl JMed. 2008;359(19):2005-2017.

95. Fooladi E, Bell RJ, Jane F, Robinson PJ, Kulkarni J, Davis SR. Testosterone improves antidepressant-emergent loss of libido in women: findings from a randomized, double-blind, placebocontrolled trial. J Sex Med. 2014;11(3):831-839.

96. Davis SR, Braunstein GD. Efficacy and safety of testosterone in the management of hypoactive sexual desire disorder in postmenopausal women. J Sex Med. 2012;9(4):1134-1148.

97. Shifren JL, et al. Testosterone patch for the treatment of hypoactive sexual desire disorder in naturally menopausal women: results from the INTIMATE NM1 Study. Menopause. 2006;13(5):770-779.

98. Wierman ME, et al. Androgen therapy in women: a reappraisal: an Endocrine Society clinical practice guideline. JClin Endocrinol Metab. 2014;99(10):3489-3510.

99. Dunaif A. Insulin resistance and the polycystic ovary syndrome: mechanism and implications for pathogenesis. Endocr Rev. 1997;18(6):774-800.
100.Franks S, Gilling-Smith C, Watson H, Willis D. Insulin action in the normal and polycystic ovary. Endocrinol Metab Clin North Am. 1999;28(2):361-378.

101. Navarro G, et al. Androgen excess in pancreatic $\beta$ cells and neurons predisposes female mice to type 2 diabetes. JCI Insight. 2018;3(12):98607.

102. Peters AA, et al. Androgen receptor inhibits estrogen receptor- $\alpha$ activity and is prognostic in breast cancer. Cancer Res. 2009;69(15):6131-6140.

103. Castellano I, et al. Androgen receptor expression is a significant prognostic factor in estrogen receptor positive breast cancers. Breast Cancer Res Treat. 2010;124(3):607-617.

104.Park S, et al. Androgen receptor expression is significantly associated with better outcomes in estrogen receptor-positive breast cancers. Ann Oncol. 2011;22(8):1755-1762.

105. Goldenberg IS. Testosterone propionate therapy in breast cancer. JAMA. 1964;188:1069-1072.

106. Talley RW, Haines CR, Waters MN, Goldenberg IS, Olson KB, Bisel HF. A dose-response evaluation of androgens in the treatment of metastatic breast cancer. Cancer. 1973;32(2):315-320.

107. Agoff SN, Swanson PE, Linden H, Hawes SE, Lawton TJ. Androgen receptor expression in estrogen receptor-negative breast cancer. Immunohistochemical, clinical, and prognostic associations. Am JClin Pathol. 2003;120(5):725-731.

108. He J, et al. Prognostic value of androgen receptor expression in operable triple-negative breast cancer: a retrospective analysis based on a tissue microarray. Med Oncol. 2012;29(2):406-410.

109. Tang D, Xu S, Zhang Q, Zhao W. The expression and clinical significance of the androgen receptor and E-cadherin in triple-negative breast cancer. Med Oncol. 2012;29(2):526-533.

110. Choi JE, Kang SH, Lee SJ, Bae YK. Androgen receptor expression predicts decreased survival in early stage triple-negative breast cancer. Ann Surg Oncol. 2015;22(1):82-89.

111. Rechoum Y, et al. AR collaborates with ER $\alpha$ in aromatase inhibitor-resistant breast cancer. Breast Cancer Res Treat. 2014;147(3):473-485.

112. De Amicis F, et al. Androgen receptor overexpression induces tamoxifen resistance in human breast cancer cells. Breast Cancer Res Treat. 2010;121(1):1-11.

113. Auricchio F, Migliaccio A, Castoria G. Sexsteroid hormones and EGF signalling in breast and prostate cancer cells: targeting the association of Src with steroid receptors. Steroids. 2008;73(9-10):880-884.

114. Cochrane DR, et al. Role of the androgen receptor in breast cancer and preclinical analysis of enzalutamide. Breast Cancer Res. 2014;16(1):R7.

115. D'Amato NC, et al. Cooperative dynamics of AR and ER activity in breast cancer. Mol Cancer Res. 2016;14(11):1054-1067.

116. He L, et al. Targeting androgen receptor in treating HER2 positive breast cancer. Sci Rep. 2017;7(1):14584.

117. Gordon MA, et al. Synergy between androgen receptor antagonism and inhibition of $\mathrm{mTOR}$ and HER2 in breast cancer. Mol Cancer Ther. 2017;16(7):1389-1400.

118. Gucalp A, et al. Phase II trial of bicalutamide in patients with androgen receptor-positive, estrogen receptor-negative metastatic breast cancer. Clin Cancer Res. 2013;19(19):5505-5512.

119. Traina TA, et al. Enzalutamide for the treatment of androgen receptor-expressing triple-negative breast cancer. J Clin Oncol. 2018;36(9):884-890.

120. Bonnefoi $\mathrm{H}$, et al. A phase II trial of abiraterone acetate plus prednisone in patients with triplenegative androgen receptor positive locally advanced or metastatic breast cancer (UCBG 12-1). Ann Oncol. 2016;27(5):812-818. 